\title{
Closed extensor tendon rupture and distal radial fracture with use of a gymnast's wrist support
}

\author{
P. R. Stuart FRCS and P. J. Briggs FRCS \\ The Hand Service, Department of Orthopaedics, Middlesbrough General Hospital, Middlesbrough, Cleveland \\ UK
}

\begin{abstract}
We report a case of delayed closed rupture of the tendon of extensor indicis proprius in a skeletally immature individual. This occurred following a minor greenstick fracture during use of a gymnast's wrist-finger support. To our knowledge this unusual complication has not been described previously.
\end{abstract}

Keywords: Tendon rupture, fracture, gymnast's wrist support

A 16-year-old male gymnast sustained an injury to the right wrist while on the high bar. The leather wrist-finger support stuck on the bar causing a hyperflexion injury. The support is placed over the fingers and held in place by a canvas strap around the forearm (Figure 1).

At the time of his admission, $4 \mathrm{~h}$ after injury, he had no neurovascular deficit and full hand function. Radiographic examination revealed an angulated greenstick fracture of the distal radius (Figure 2), which was manipulated into an anatomical position under general anaesthesia. There was full forearm rotation with no subluxation of the distal radioulnar joint. An above-elbow plaster-of-Paris cast was applied with the forearm in supination. On discharge the following day he was pain free and had full neurovascular and tendinous function. The patient noted inability to extend his right index finger 3 days after injury. He did not seek advice until his routine follow-up appointment 1 week after injury. At this time the absence of active extension of the index finger was confirmed. He reported no pain under the cast, the radiography showed maintenance of the anatomical reduction of his fracture. The cast was removed to allow full examination of the hand and wrist. The inside of the cast was smooth and had not caused localized pressure on the skin. A tense swelling was present in the fourth extensor compartment.

Surgical exploration of the fourth extensor compartment confirmed the presence of a large haem-

Address for correspondence: Mr P. R. Stuart FRCS, The Hand Service, Department of Orthopaedics, Middlesbrough General Hospital, Ayresome Green Lane, Middlesbrough, Cleveland TS5 5AZ, UK

(C) 1993 Butterworth-Heinemann Ltd 0306-3674/93/020092-02 atoma. The extensor indicis proprius tendon was contused and ruptured at the musculotendinous junction. The extensor communis slip to the index finger was also badly contused but found to be intact.

The distal stump of the ruptured tendon was tenodesed to the intact communis slip. The patient made a satisfactory postoperative recovery. At 3 months after surgery he had full forearm and hand function, including full finger extensor power and no extensor lag (Figure 3).
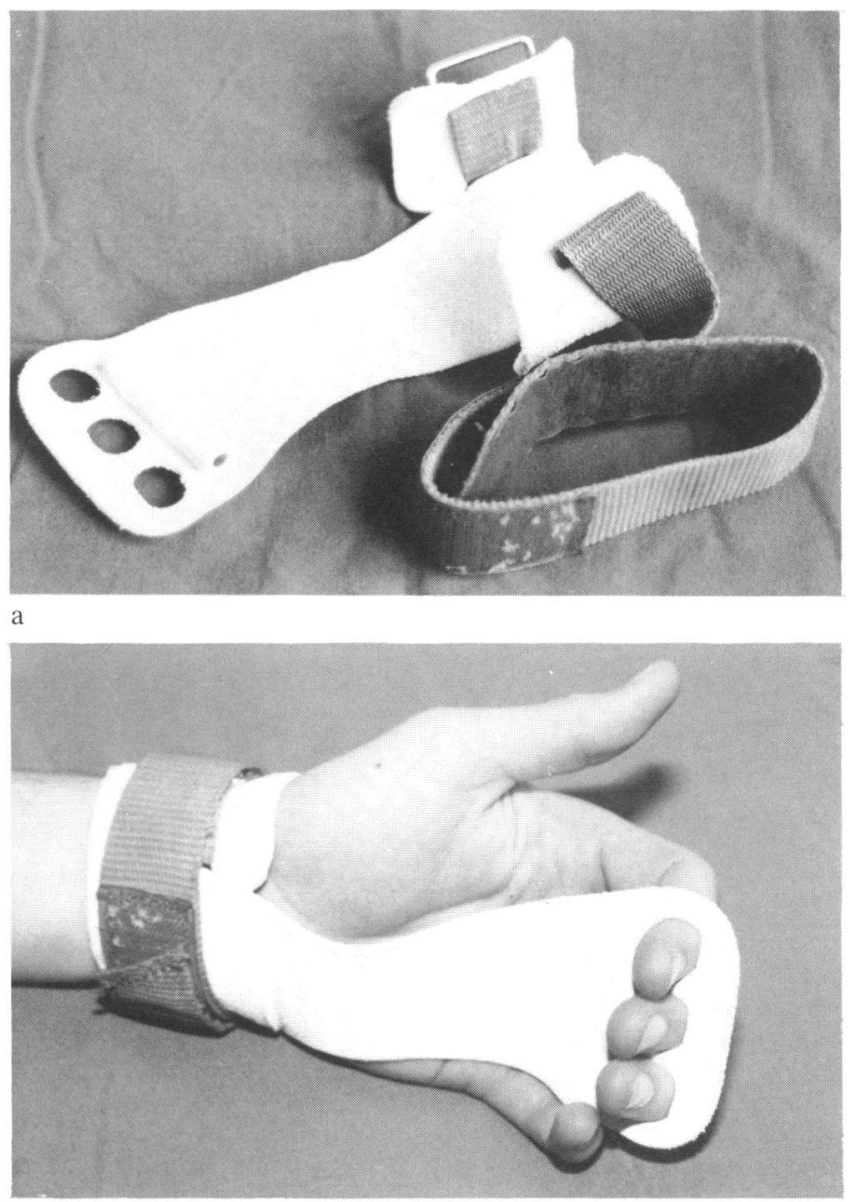

b

Figure 1. a Leather wrist-finger splint used to improve grip on the high bar. $b$ The splint in position 

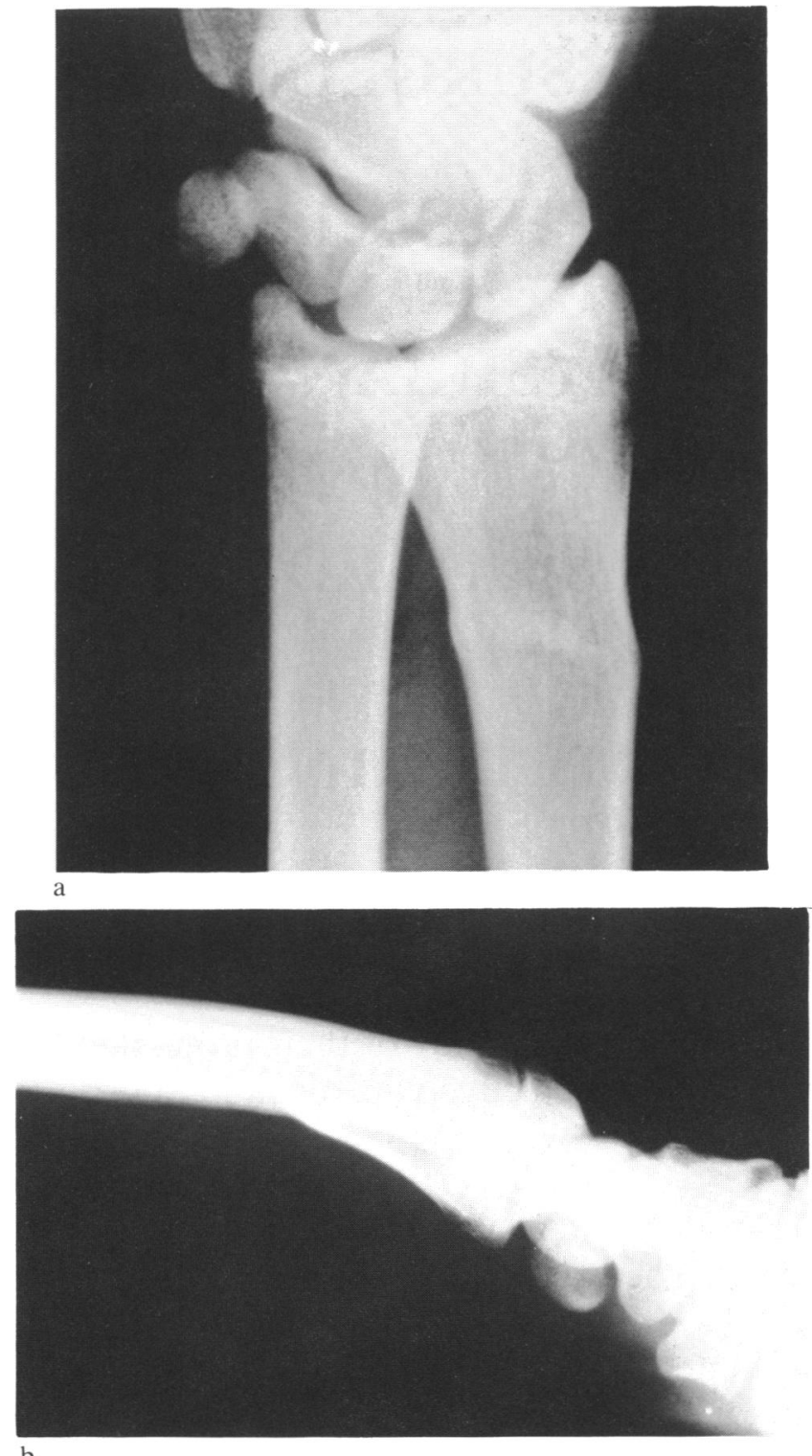

Figure 2. a Anteroposterior radiograph of the fracture. b Lateral radiograph of the fracture

\section{Discussion}

In patients without inflammatory arthritis, extensor tendon rupture is most commonly reported as a complication of minimally displaced Colles' fractures $^{1,2}$. The commonest tendon involved is that of extensor pollicis longus ${ }^{3-6}$. Closed rupture or entrapment of the finger extensor tendons have been reported with a variety of other fractures, including Smith's ${ }^{7,8}$, Galleazzi's ${ }^{8}$, scaphoid ${ }^{9}$, severely displaced wrist fractures ${ }^{10}$ and subluxed distal radioulnar joints $^{9,11}$. To our knowledge there have been no previous reports of closed delayed rupture of an extensor tendon complicating such a minimally displaced juvenile-type fracture. We suggest that the tensile forces generated in the extensor compartment after adhesion of the wrist support to the bar resulted in damage sufficient to initiate late rupture.

We therefore stress the importance of proper lubrication of these and similar supports during gymnastic exercises.

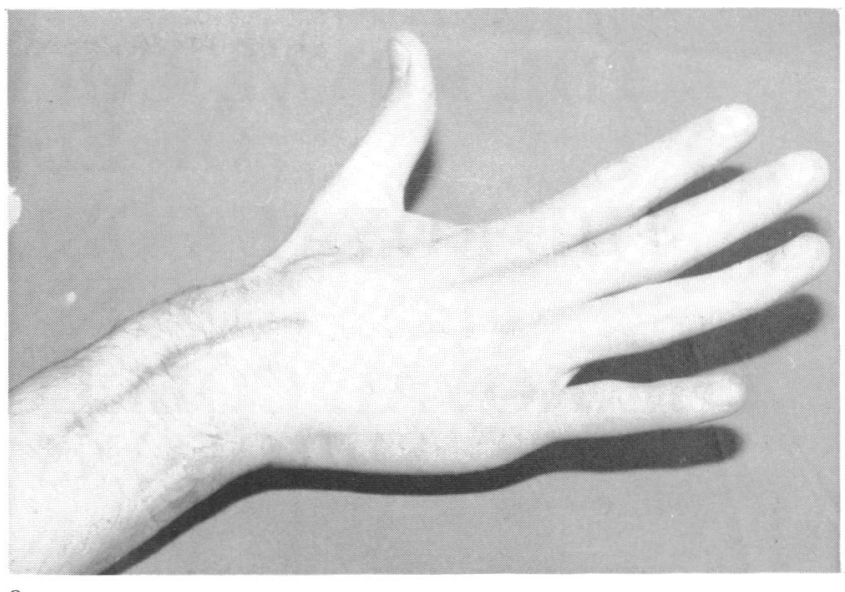

a

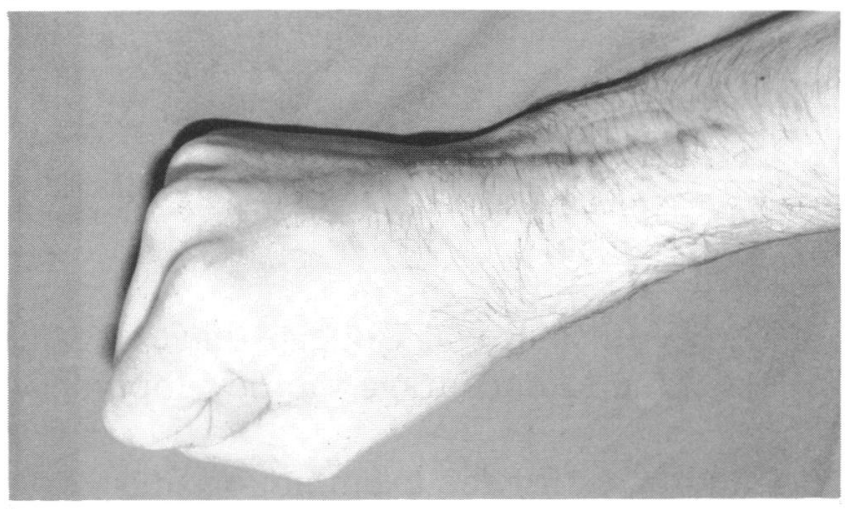

Figure 3. a,b Hand function at discharge

\section{Acknowledgements}

The authors wish to thank Mr J. Stothard and Mr R. J. Montgomery for allowing us to report their case.

\section{References}

1 McMaster PE. Late rupture of extensor and flexor pollicis longus tendons following Colles' fracture. J Bone Joint Surg 1932; 14: 93-101.

2 Sadr B. Sequential rupture of extensor tendons after a Colles' fracture. J Hand Surg [Am] 1984; 9-A: 144-5.

3 Bunata RE. Impending rupture of the extensor pollicis longus tendon after a minimally displaced Colles' fracture. $J$ Bone Joint Surg [Am] 1983; 65A: 401-2.

4 Helal B, Chen SC, Iwegbu G. Rupture of the extensor pollicis longus tendon in undisplaced Colles' type of fracture. Hand 1982; 14: 41-7.

5 Strandell G. Post-traumatic rupture of the extensor pollicis longus tendon; pathogenesis and treatment: survey based on 208 cases, including 14 personal cases. Acta Chirurgica Scandinavica 1955; 109: 82-96.

6 Engkvist O, Lundborg G. Rupture of the extensor pollicis longus tendon after fracture of the lower end of the radius: a clinical and microangiographic study. Hand 1979; 11: 76-86.

7 Uchida Y, Sugioka Y. Extensor tendon rupture associated with Smith's fracture. Acta Orthop Scand 1990; 61: 374-5.

8 Itoh Y, Horiuchi Y, Takahashi M, Uchinishi K, Yabe Y. Extensor tendon involvement in Smith's and Galeazzi's fractures. J Hand Surg [Am] 1987; 12-A: 535-40.

9 Harvey FJ, Harvey PM. Three rare causes of extensor tendon rupture. J Hand Surg [Am] 1989; 14-A: 957-62.

10 Gladstone $\mathrm{H}$. Rupture of the extensor digitorum communis tendons following severely deforming fractures about the wrist. J Bone Joint Surg [Am] 1952; 34-A: 698-700.

11 Vaughan-Jackson OJ. Rupture of extensor tendons by attrition at the inferior radioulnar joint. J Bone Joint Surg [Br] 1948; 30-B: 528-30. 